\title{
The Academic Intrinsic Motivation and its Relationship with the Emotional Intelligence Level with a Sample of the Academic Overachievers and Underachievers of Najran University
}

\author{
Dr Ibrahim Ragab Abbas Ibrahim \\ Department of Special Education, Najran University, KSA \\ E-mail: Hima_abbas2009@yahoo.com \\ Dr Weal Ameen AL-Ali \\ Department of Special Education, Najran University, KSA \\ E-mail: waaaaalali@yahoo.com / waalali@nu.edu.sa
}

Received: March 31, 2016 Accepted: April 24, 2016 Published May 1, 2016

doi:10.5296/jse.v6i2.9234 URL: http://dx.doi.org/10.5296/jse.v6i2.9234

\begin{abstract}
The research tackled the academic intrinsic motivation and its relationship with the emotional intelligence with a sample of the academic overachievers and underachievers of Najran University. The study population consisted of the students of Najran University who are enrolled in the University academic year 2015/2016, during the first semester in the various colleges. The study sample consisted of (423) male and female students; and the study instruments included the emotional IQ which consisted of (54) items, and the academic intrinsic motivation questionnaire, which consisted of (36) items, to identify the overall emotional intelligence degree and the motivation with the students. The results showed that the academic intrinsic motivation and emotional intelligence degrees were high with the university students. Furthermore, the results showed a direct correlational, statistically significant relationship between the academic intrinsic motivation and the emotional intelligence; and there are statistically significant differences between the motivation and emotional intelligence among the academically outstanding and non-outstanding students.
\end{abstract}

Keywords: emotional intelligence, academically outstanding students, non-outstanding students, Najran University. 


\section{Introduction}

Motivations are the most important topic in psychology, which are also more interesting to the educators. In this concern, the teacher is highly concerned to know the motivations of the students and their attitudes, to enable him/her utilize them in stimulating them to learn. In this concern, Ford et al (1998, pp.28-33) maintain that the lack of motivation with the student is a crucial and persisting problem in the educational system; and teachers are frustrated because some students lack excitement and commitment with respect to mastering the concepts.

Hussein (2005:3) believes that motivation is innate, and could be acquired through study and research. Children are born with the motivation of the learning inheritance, which appears with all the individuals and in different cultures. Children may develop it by providing them the agitators and activities, because they directly affect them and play a major role in the pupils' learning process.

Friar (1995) sees that students with the high intrinsic motivation come to the educational work enthusiastically and actively, and that they put on their best efforts to gain the highest degrees. Cloninger (1996: 260-261) believes that students in the educational environments learn more with intrinsic motivation, in other words, when they enjoy what they learn. She adds that intrinsic motivation is the energy stemming from the curiosity; and that self-motivated students obtain higher degrees than the normal students in the examinations on the abilities, in spite of the fact that certain individuals are motivated by both internal and external factors, at the same time.

Sternberg (1998: 530) distinguishes between two types of motivations, the intrinsic motivation and extrinsic motivation, as follows: the intrinsic motivation is powers coming from inside the person stimulating him/her to go deeper to work volitionally, and enjoyably. On the contrary, the extrinsic motivation is of an external source, which encourages the person to complete the tasks, either for being rewarded, or in avoidance of punishment.

Recently, psychologists began considering that the intelligence forms only a small proportion of the success components in life; and the remaining portion of success is attributed to the emotional equilibrium and temperamental traits, i.e. the emotional intelligence (Abu Al-Naser, 2008: 103).

Goleman (1995:13) outlined that $80 \%-90 \%$ of the professional success could be ascribed to factors other than the cognitive intelligence. Mayer et al (2000: 396) maintained that the emotional intelligence is the best predictor of success in the life. It is built on the idea that the individual's success in the social or professional life does not depend on what he/she owns of mental abilities (cognitive intelligence), but on what he/she owns of emotional and social skills that form the components of this intelligence (Sala, 2001).

The overachievers are characterized by that they are socially adapted and emotionally stable, confident of themselves, distinguished by a high level of moral thought and reasoning, emotional participation, very ambitious, and tending to accept risk and seeking for perfection (Zahlouq, 2001: 9-55). 
Some studies indicated that the university young students of the promising qualifications failed in their practical lives. This failure may be related to their poor emotional intelligence skills, which is negatively reflected on their communication with the others, and on their motivation. This is quite contrary to those who possess high level of emotional intelligence, who have the intrinsic motivation for accomplishment, and expect their success. Stimulating the motivation is one of the basic elements of emotional intelligence, because the emotional skills lead the individual toward the objectives, and facilitate achieving them (Shabbier and Laurence, 2004).

Shabeeb (1999: 207-274) and Darwish (2002: 233-241) indicate that the most determinants of the academic intrinsic motivation with the university students (of both genders) are: level of ambition, positive direction of learning, persistence, curiosity, self-efficiency, motivation for accomplishment, enjoyment during learning, fear of failure, and the cognitive motivation.

There are certain ingredients that accounted for the largest portion of definitions, which we relied upon in this research, as they are the most frequent. Namely: persistence in learning, enjoyment during learning, and concentration during learning on performing the tasks assigned to the student (Sha'aban, 2005).

The emotional intelligence theory is one of the modern theories that emerged to alert to the status of the emotional system in the cognitive system of the human abilities. At the same time, it came to stand in the face of the conventional doorways, which used to consider the emotions a system that impedes the cognitive activity, and a system that is discrete from intelligence. As such, the turning point showed that the emotional intelligence is a result of the integration of the two systems of cognition and emotion; as the abstract, inferential cognitive system orients the emotion, meanwhile, the emotional system reinforces the cognitive ability (Mayer, 2001).

The emotional intelligence concept appeared recently in the literatures of Bar-On (1988); Gardener (1983); and Salovey and Mayer (1990). Bar-On defined it as the individual's ability for understanding his/her feelings and expressing them out; possessing a positive self-evaluation; wide realization of his/her abilities; and the ability to establish mature and responsible social relations, without transforming them into dependency on others. In this concern, people who have high levels of emotional intelligence are characterized by optimism, resilience, realism, success in problem solving, and dealing with pressures without losing control (Bar-On, 1997). Abraham (2000) defined it as "a pool of skills to which accuracy in estimating and correcting the self-feelings is ascribed, as well as the discovery of the emotional features of others and utilizing them for motivation and achievement in the individual's life." Furnham (2006) defined it as 'the ability of conceiving, understanding and tackling the emotions, and organizing the feelings so that the individual becomes able to influence the feelings of the others."

Al-Saheb and Ahmad (2014) conducted a study aimed at identifying the relationship between the positive thinking, the intrinsic motivation, and the direction toward the teaching career. The study sample consisted of (344) male and female students of the education colleges at Baghdad and Al-Mustanssiriah Universities during the academic year 2012-2014. The 
researchers employed three instruments, the positive thinking scale, the academic intrinsic motivation scale and the direction toward the teaching profession scale. The results indicated a positive correlational and statistically significant relation between the positive thinking, the intrinsic motivation, and the direction toward the teaching career.

Lupu (2012) conducted a study aimed to identify the relation between the emotional intelligence and sympathy with the overachievers and underachievers. The study sample consisted of (114) overachievers, and (57) underachievers, and employed the emotional IQ developed by Gaius, and the emotional sympathy scale. The results showed that the overachievers obtained higher grades on the emotional IQ; and that the emotional sympathy serves as an indicator (predictor) of the emotional intelligence.

Al-Gharaibeh (2011) made a study to explore the level of the emotional intelligence with a sample of the overachievers and normal students at Al-Qassim area. He employed the emotional intelligence test developed by Othman and Rezeq (2002). The results of the study showed statistically significant differences in the emotional intelligence level between the overachievers and normal students, in favor of the overachievers.

Al-Mallali (2011) conducted a study aimed at identifying the differences between the overachievers and normal students in the dimensions of the emotional intelligence; and whether there are differences in the emotional intelligence depending on the overachieving and gender (males, females) variables. The study concluded that there are significant differences among the responses of the overachievers and normal students in the dimensions, all of which are in favor of the overachievers, save for the management of pressures. The study further did not find differences between the males and females of the overachievers and normal students in all the dimensions; and that there are differences between the overachievers and normal male students on the dimensions of social efficiency, adaptation, general mood, positive impression, and the overall grade, in favor of the overachievers. The study also indicated that there are differences between the responses of the female overachievers and normal students on the dimensions of the personal efficiency, adaptation and the overall degree, in favor of the female overachievers.

The study of Al-Alwan and Al-Atiyyat (2010) aimed at exploring the relationship between the academic intrinsic motivation and the academic achievement, with a sample of the 10th basic graders in the City of Ma'an, Jordan. The study consisted of (111) male and female students; out of them (62) students were high achievers and (49) were low achievers. The researchers employed the academic intrinsic scale developed by Lepper (2005). The study results revealed direct correlational, statistically significant relationship between the students' academic intrinsic motivation and the academic achievement; and that there are differences between the students in the academic intrinsic motivation in favor of the high achievers. Meanwhile, the results did not show differences among the males and females in the academic intrinsic motivation; and indicated that we may predict the students' achievement through our knowledge of their academic intrinsic motivation.

Babelan (2010) conducted a study aimed to reveal the role of the emotional intelligence in predicting the academic achievement and motivation for achievement with the 
remote-learning system students. The sample included 328 male and female students of Noor University Payama in the academic year 2008-2009, who underwent the emotional intelligence and motivation for achievement tests, to identify their achievement. The results showed that the dimensions of the emotional intelligence have a statistically significant relationship with the academic achievement. It further showed the importance of the emotional intelligence, with a statistical significance, in increasing motivation for achievement, personal relations and awareness of the students. However, the study did not show differences between the males and females in the emotional intelligence tests, but there were differences in the motivation for the academic achievement, in favor of the females. Finally, there were no differences on the emotional intelligence quotient and the achievement motivation ascribed to the specialization (major) variable.

Qualter, Whiteley, Morley \& Dudiac (2009) conducted a study to identify the relationship between the emotional intelligence, persistence to learn, and success in the university. The study sample consisted of (465) university students, and concluded that the students who have a higher level of emotional intelligence are the most susceptible to success and promotion to the next level. The study also showed that the students who develop the emotional intelligence level became more persistent to learn.

The study of Abdul-Razzaq (2008) aimed to clarify the relationship of the emotional intelligence with each of the creative thinking and the achievement motivation, among the female students of the Faculty of Education, King Saud University; and to carry out a comparison between the overachievers and underachievers. The study was carried out on a sample of 223 high and low achiever female students, and employed the emotional intelligence and motivation for achievement scales, as well as Torrance creative thinking scale. The results showed a statistically significant correlational relationship between the emotional motivation and the creative thinking, in favor of the female overachievers; and showed differences between the academic years, in favor of the fourth academic year students.

Al-Masri (2007) made a study that aimed to identify the differences in the emotional intelligence among the academically overachievers and the normal students of both genders. The sample consisted of (98) students, out of them are 25 males and 73 females, of the Faculty of Educational Science students in Isra University (Private), Jordan, where the emotional intelligence scale was applied. The study made a number of results, most important are that there is an excellence of the females over the males on the sympathy dimension, and the overall scale. On the other hand, there were no statistically significant differences in the emotional intelligence between the high achievers and normal students, neither on the overall scale nor on the sub-dimensions of the scale.

Kammour (2013) provided a study to identify the relationship between the motivation for achievement and emotional intelligence. The study sample consisted of (201) male and female students of the Arab Open University; and the researcher employed Bar-On scale for emotional intelligence and motivation for achievement. The results showed direct correlational relationship between the level of emotional intelligence and motivation for 
achievement; and that there were no differences on the two scales that may be ascribed to the gender or specialization (major) variables.

This study came out with the following inquiry:

What is the relationship between the intrinsic academic motivation and the emotional intelligence level with the academic overachievers and underachievers of Najran University students?

What is the level of the academic intrinsic motivation with the students of Najran University? And, what is the level of the emotional intelligence with them?

Is there a correlational relationship between the academic intrinsic motivation and the emotional intelligence?

Are there differences in the levels of the academic intrinsic motivation and the emotional intelligence dependent on the accumulative average (academic excellence) variable?

\section{Method}

\subsection{Research Method}

The researchers employed the descriptive, correlational, comparative method, to define the relationship between the academic intrinsic motivation and the emotional intelligence; and to identify the differences between the overachievers and underachievers.

\subsection{Study Population and Sample}

The study population comprised students of Najran University who are enrolled for the first semester of the academic year 2015/2016. The study sample included (423) male and female students of the various university colleges, of both the high achievers and low achievers, who were randomly chosen for each group. The accumulative average was the base for categorizing the students according to the academic excellence variable. The grade (from 4 to 5) was taken as an overachieving criterion and the accumulative average (3.99 and less) for the underachievers.

\subsection{Instruments}

- Emotional Intelligence Scale: emotional intelligence scale, prepared by Othman and Rezeq (2002), which consists of (58) items, was employed. The scale includes five dimensions (emotional cognition, emotion management, emotion organization, sympathy and communication), graded as per Likert's five-point scale. This scale was previously codified according to the Saudi environment, through studies such as Al-Abdaly (2009), and Al-Juaid (2011). In our current study, we verified the scale validity through two methods. First, validity of the arbitrators, as the scale was presented to (10) experts of the faculty members in Najran University. Their suggestions and amendments were made, and (4) items were deletes, so the scale in its final form consisted of (54) items. Second, consistency validity by applying on an exploratory sample of (44) university students outside our study sample. The 
correlation coefficients ranged between (0.34-0.71), which were all statistically significant. Furthermore, Chronbakh Alfa was used to verify the scale reliability, which was $(0.83)$.

- Academic Intrinsic Motivation Scale: it was prepared by referring to the previous literature and consisted of (44) items, graded according to Likert's five-point scale. We verified the scale validity through two methods. First, validity of the arbitrators, as the scale was presented to (10) experts of the faculty members in Najran University. Their suggestions and amendments were made, and (8) items were deletes, so the scale in its final form consisted of (36) items. Second, consistency validity, as the correlation coefficients ranged between $(0.31$ and 0.68), which were all statistically significant. Furthermore, Chronbakh Alfa was used to verify the scale reliability, which was $(0.77)$. To analyze the results, they were categorized into three levels (low, medium and high) as follows: (1-2.33) low, (2.34-3.67) medium, and (3.69-5) high.

\subsection{Study limitation}

Temporal: the first semester of the academic year 2015/2016

Spatial: Najran University

\subsection{Research Terms}

- Academic Intrinsic Motivation: defined by Shebeeb (1994: 146-147) as "Students' enjoyment of learning, interest in modernity, curiosity, persistence in performing difficult tasks; and is characterized by challenge, realization of efficiency, and excellence in all what they carry out." It is expressed by the grade the student obtains on the motivation scale.

- Emotional Intelligence: defined by Goleman (2005) as our ability to know our feelings and the feelings of others; and to realize ourselves, mange our emotions, and our relations with the others, in an effective manner. It is expressed by the grade the individual obtains on the emotional intelligence scale.

- Academic Overachievers: those who obtain higher noticeable degrees in the academic achievement. It is expressed by the high average, which was determined at 4 out of five in the accumulative average, as a scale for the excellence of the overachieving students.

- Underachievers: those who obtain lower average than the overachievers.

\section{Results}

3.1 Results of the first question stating, "What is the level of the academic intrinsic motivation and the emotional intelligence with the students of Najran University?" The means and standard deviations were calculated as shown in table No. (1) 
Table 1. Means and Standard Deviations of the Academic Intrinsic Motivation and the Emotional Intelligence

\begin{tabular}{lcccc}
\hline & $\mathrm{N}$ & Mean & Std. Deviation & Level \\
Academic Intrinsic Motivation & 425 & 3.69 & .460 & High \\
Emotional Intelligence & 425 & 3.64 & .400 & High \\
\hline
\end{tabular}

The table shows that the academic intrinsic motivation with the students of Najran University is high, and the degree of their emotional intelligence was high too.

3.2 Results of the second question stating, "Is there a correlational relationship between the academic intrinsic motivation and the emotional intelligence?" For answering this question, Pearson correlation coefficient was calculated between both, and Table No. (2) illustrates this.

Table 2. Correlation Relationship between the Academic Intrinsic Motivation and Emotional Intelligence

\begin{tabular}{|c|c|c|c|}
\hline & & $\begin{array}{l}\text { Academic Intrinsic } \\
\text { Motivation }\end{array}$ & $\begin{array}{l}\text { Emotional } \\
\text { Intelligence }\end{array}$ \\
\hline Academic Intrinsic & Pearson Correlation & 1 & $* * .277$ \\
\hline \multicolumn{4}{|l|}{ Motivation } \\
\hline Sig. (2-tailed) & & & .000 \\
\hline $\mathrm{N}$ & & 425 & 425 \\
\hline Emotional & Pearson Correlation & 1 & $* * .277$ \\
\hline \multicolumn{4}{|l|}{ Intelligence } \\
\hline Sig. (2-tailed) & & & .000 \\
\hline $\mathrm{N}$ & & 425 & 425 \\
\hline
\end{tabular}

** Correlation is significant at the 0.01 level (2-tailed)

The above table shows that the correlation coefficient is $(0.28)$, which is a statistically significant value at the significance level (0.01). Accordingly, there is a positive and direct relationship between the academic intrinsic motivation and the emotional intelligence.

3.3 Results of the second questions stating, "Are there differences in the levels of the academic intrinsic motivation and the emotional intelligence dependent on the accumulative 
average (academic excellence) variable?" For answering this question, the means and standard deviations of the motivation and intelligence level were calculated dependent on the academic excellence. Table No, (3) illustrates this.

Table 3. Means and Std. Deviations Dependent on the Academic Excellence

\begin{tabular}{|c|c|c|c|c|}
\hline & $\begin{array}{l}\text { Academic Excellence } \\
\text { Variable }\end{array}$ & $\mathrm{N}$ & Mean & $\begin{array}{l}\text { Std. } \\
\text { Deviation }\end{array}$ \\
\hline \multirow{2}{*}{$\begin{array}{l}\text { Academic } \\
\text { Motivation }\end{array}$} & Overachiever & 164 & 3.76 & .470 \\
\hline & Underachiever & 261 & 3.46 & .449 \\
\hline \multirow[t]{2}{*}{ Emotional Intelligence } & Overachiever & 184 & 4.06 & .429 \\
\hline & Underachiever & 241 & 3.85 & .357 \\
\hline
\end{tabular}

To display the significance of the differences, between the means, of the effect of the academic overachieving on the level of academic intrinsic motivation and emotional intelligence, T-test was employed, and Table No. (4) shows this.

Table 4. Significance of the Differences between the Means of the Academic Intrinsic Motivation and the Emotional Intelligence, as per the Academic Excellence

\begin{tabular}{lllll}
\hline \multicolumn{1}{c}{ Dimension } & $\mathrm{T}$ & $\mathrm{df}$ & Sig. (2-tailed) & Mean Difference \\
\hline Academic Intrinsic Motivation & 2.520 & 423 & .012 & .115 \\
\hline Emotional Intelligence & 4.562 & 423 & .000 & .209 \\
\hline
\end{tabular}

The results showed statistically significant differences of the effect of the academic excellence variable, on each of the academic intrinsic motivation and emotional intelligence, between the overachievers and underachievers.

\section{Discussion}

4.1 In general, the results showed that the level of academic intrinsic motivation was high with students. One could say that the age group of the university students has its role in the development of the academic intrinsic motivation with them. They are aware that they are now living the future preparation stage, and that the forthcoming opportunities availed for them later, work or higher studies, all depend on the high academic performance. In other words, whoever performs better will have better opportunities. Therefore, we find the self-interest and the motivation are high with them. The results further showed that the emotional intelligence level was high, as they are in the begging of their puberty stage, in which the individual seeks success, achievement, and self-assurance. Moreover, in this stage, 
the individual is more capable to manage his/her relationships with the others, understand and organize his/her emotions and feelings. These findings were assured in the study conducted by Qualter et al (2009), which indicated that the students who possess higher levels of emotional intelligence are the more successful, promoted to the next higher position, and are more persistent in their study. In addition, the university serves as a facilitator of the obstacles before the students, and motivate them for excellence, on one hand, and refines their personalities and develops their skills, through the extracurricular activities provided for them, on the other.

4.2 The results showed a positive, statistically significant, and direct correlational relationship between the academic intrinsic motivation and the emotional intelligence. In other words, the more of emotional intelligence, mean the more of motivation, and vice versa. In this concern, the students with the emotional intelligence are mostly of high motivation, having more interest to learn. In addition, they are more effective and active in the learning process, and have an endeavor to realize the higher academic achievement. This study is in line with the study of Al-Alwan and Al-Atiyyeh (2010), that there is a direct correlational relationship between the academic intrinsic motivation and the academic achievement. It is also in agreement with the study of Abdul-Razzaq and Kammour (2013), that there is a direct correlational relationship between the emotional intelligence and the motivation for achievement; and the study of Babelan (2010), which indicated that the dimensions of the emotional intelligence have a statistically significant relationship with the academic achievement.

4.3 The results further showed that there are statistically significant differences in the academic intrinsic motivation and the emotional intelligence between the academic overachievers and underachievers, in favor for the former. This is quite an expected result, since the overachievers have higher motivation for achievement; are more concentrating and active during the learning process; more persistent and eager to master their works; and possess the emotional equilibrium and compatibility with the changes more than the others. This study is in agreement with that of Al-Alwan and Al-Atiyyeh (2010), that the overachievers have more academic intrinsic motivation than the underachievers. It is also in line with the study of Al-Gharaibeh (2010) that the talented students were of more emotional intelligence than their normal peers. The study is further in agreement with that of Al-Mallali (2010), which indicated differences in the emotional intelligence among the students, in favor of the overachievers.

\section{Recommendations}

The researchers recommend setting programs for the development of the emotional skills, such as guidance programs for the universities, and programs for the development of the academic intrinsic motivation.

\section{Suggestions}

Constructing guidelines programs for the development of the emotional intelligence and academic intrinsic motivation with the students of the different education stages. 
- Study of the relationship of the emotional intelligence with other variables.

\section{Acknowledgments}

The researchers would like to extend their gratitude to the Deanship of Scientific Research at Najran University for funding this research project, under the grant number (NU/SHED14/072).

\section{References}

Abraham, R. (2000). The Role Of Job Control As a Moderator Of Emotional Dissonance And Emotional Intelligence. Journal Of Psychology Interdisciplinary \& Applied, 134, 169-171. http://dx.doi.org/10.1080/00223980009600860

Abu Al-Naser, M. (2008). Developing the Emotional Intelligence is a Gateway to Excellence at Work and Success in Life, Cairo, Dar Al-Fajr for Publication and Distribution.

Abu Dhaif, E. (2012). The Emotional Intelligence and its Relationship with Motivation for Achievement among a Sample of the Visually-Disabled Adolescents, The Educational Journal, Sohag University, 31, 67-117.

Al-Abdali, S. (2009). The Emotional Intelligence and its Relationship with each of the Self-Efficacy and Marital Adjustment among a Sample of the Married Male Teachers in Mecca Mukarramah City, Unpublished MA Thesis, Saudi Arabia, Umm Al-Qura University.

Al-Alwan, A., \& Al-Atiyyat, K (2010). The relationship between the academic intrinsic motivation and the academic achievement among a sample of the 10th graders in the city of Ma'an, Jordan. The Islamic University Journal, 18(2), 683-717.

Al-Gharaibeh, S. (2011). Emotional intelligence with the talented and normal students of the intermediate stage in Al-Qassim A comparative study. Islamic University Journal, 19(1), 567-596.

Al-Ju'aid, M. (2011). The Emotional Intelligence and its Relationship with Socio-Psychological Adaptation among Tabuk University Students, Kingdom of Saudi Arabia", Unpublished MA Thesis, Mutta University, Jordan.

Al-Mallali, S. (2011). Differences in the Emotional Intelligence with the Overachievers and Normal Students (A Field Study on the First Secondary Grade Students in Damascus). Damascus University Journal, 27(102), 283-320.

Al-Masri, M. (2007). Emotional Intelligence: Comparative Study among the Overachievers and Normal Students of the University Stage. Faculty of Education Journal, Ain Shams University, No. 31.

Al-Saheb, Muntaha, \& Ahmad, Suzan Duraid. (2014). The Positive Thinking and its Relationship with the Academic Intrinsic Motivation and the Trend toward the Teaching Career among the Education Colleges Students. Educational and Psychological Research Magazine, Baghdad University, 41, 113-142. 
Babelan. A. Z. (2010). The role of Emotional intelligence in predicting students academic achievement in distance education System. Procedia - Social and Behavioral Sciences, 2(2), 1157.

Bar-On, R. (1997). Bar-On Emotional Quotient Inventory: Technical Manual, Toronto : Multi-Health Systems Inc.

Chan, W. (2008). Giftedness of Chinese Students in Hong Kong. Gifted Child Quarterly, 52(1), 40-54. http://dx.doi.org/10.1177/0016986207311058

Cloninger S. C. (1996). Personality, Description, Dynamics and Development. Freeman and Company. New York, 260- 261.

Darwish, H. (2002). Differences in Certain Dimensions of the Intrinsic Motivation between the Cheaters and Non-cheaters of the University Students. Faculty of Education Journal, Al-Azhar University, 114, 219-261.

Ford, D. Y., Alber, S. R., \& Heward, W. L. (1998). Setting motivation traps for underachieving gifted students. Gifted Child Today Magazine, 21(2), 28-33.

Friar, F. (1995). The Intrinsic Motivation for Study among the Second Preparatory Graders. Faculty of Education Journal, Zagazig University, Part 1, 24, 115-137.

Furnham, A. (2006): Trait Emotional Intelligence and Happiness, Social behavior and Personality, 31(8), 815- 824.

Gardner, H. (1993). Multiple Intelligence. New York: Basic Books.

Goleman, D. (1995). Emotional Intelligence: why it can matter more than IQ. New York. Basic Books.

Hussein, R. (2005). Effect of a Proposed Training Program on Certain Components of the Academic Intrinsic Motivation with a Sample of the Second Round Students of the Basic Education. Unpublished Ph.D. Dissertation, Faculty of Education, Al-Azhar University.

Kammour, M. (2012). Achievement Motivation and its Relationship with the Emotional Intelligence Level among the Arab Open University Students/Jordan Branch", Jerusalem Open University Journal for Educational and Psychological Studies, 2, 2013.

Laurence, S. (2014). How to Upbring a Child Enjoying Emotional Intelligence? Kingdom of Saudi Arabia, Jarir Library.

Lupu, V (2012). Emotional intelligence in gifted and non- gifted high school students, Buletinstintific, 17(2), 128-132.

Mayer, J. D. (2001b). Emotion, Intelligence, and emotional intelligence. In Forgas, J. P, Handbook of Affect and Social Cognition. Mahwah,NJ: Lawrence Erlbum Associates,Publishers.

Mayer, J., Salovey, P., \& Caruso, D. (2000). Models Intelligence, In R Sternberg (ED.) Handbook of intelligence (369-420). Cambridge, UK: Cambridge University Press. 


\section{Macrothink}

Nassar, W. (2008). Emotional Intelligence and its Relationship with each of the Innovative Thinking and the Achievement Motivation with the Female Students of Psychology Department, Faculty of Education, King Saud University (A Comparative Study between the Overachievers and Underachievers). Faculty of Education Journal, 1(35). Al-Azhar University.

Othman, F., \& Rezeq, M, (2002); Emotional Intelligence Scale, its Concept and Measurement. Cairo, Dar-el-Fkir Alarabi.

Qualter, P.; Whiteley, H.; Morley, A., \& Dudiac, H. (2009). The Role of Emotional Intelligence in the Decision to Persist With Academic Studies in High Education. Research in Post-Compulsory Education, 14(3), 219231. Communities and nations. Sep 2009, 9(4), 135 144.

Rajeh, I. (1995). Fundamentals of Psychology, Cairo, Dar-el-Ma'aref.

Sala, F. (2001). It's lonely at the top executives, emotional intelligence self. (MIS) perceptions Elections visional consortium for research on emotional intelligence in organizations, ay/McBer, Retrived September 26, 2005 from www.eiconsortium.org.

Shebeeb, A. (1994). A Factorial Study of the Academic Motivation with the University Students of both Genders. Faculty of Education Journal, Al-Azhar University, August 1999, No. 83, 208-273.

Shebeeb, M. (1994). The Developmental Direction of the Academic Intrinsic Motivation in the Different Age Stages among Both Genders", The Egyptian Journal for the Educational Evaluation, 2(1), 140-210.

Shebeeb, M, M. (2003). Effect of the Use of a Strategy to Reinforce the Autonomy of the Academic Motivation of the Students of the Teachers' College in Kingdom of Saudi Arabia. Faculty of Education Journal, Al-Azhar University, No. 118,171-246.

Sternberg J. R. (1998). In search of The Human Mind. Harcourt Brace College Publisher.

White, R. W. (1959). Motivation reconsidered the concept of competence. Psychological review, 66, 297-333.

Zahlouq, M. (2001).The Overachievers in Damascus University, Their Factuality and Problems: A Field Study. Damascus University Journal for Educational Science, 17(1), 9-55. 